\title{
The Impact of Rate Regulation in U.S. Property-Liability Insurance Markets: A Cross-Sectional Analysis of Individual Firm Loss Ratios
}

\author{
by J. David Cummins* and Scott E. Harrington*
}

\section{Introduction}

Rates in the competitively structured United States property-liability insurance market are subject to some form of prior approval law in about one half of the states. These laws generally prohibit rate changes by insurers unless active regulatory approval is given or a waiting period has expired at which time rates are "deemed" to be approved. The remaining states have competitive rating laws that allow insurers pricing freedom. Most competitive rating laws have been enacted to replace prior approval laws since the late 1960s.

Numerous studies have analyzed whether prior approval regulations affects rates by comparing aggregate statewide loss ratios in prior approval and competitive rating states (see Harrington [1984b]). Most of these studies have analyzed data for automobile insurance only. ${ }^{1}$ The results commonly have indicated a positive impact of rate regulation on loss ratios. While the estimated impact has not always been statistically significant (e.g., Ippolito [1979], the U.S. General Accounting Office [1979], and Witt and Urrutia [1983b]), the most recent work suggests that rate regulation increased auto insurance loss ratios during the late 1970s and early 1980s (see Harrington [1984a, 1986], Grabowski, Viscusi, and Evans [1985], and Pauly, Kunreuther, and Kleindorfer [1986]). ${ }^{2}$ Little is know about whether the implied negative impact on prices has resulted in reduced product quality or whether insurers have been able to recoup losses in regulated states from other lines of business or from business in unregulated states.

This study uses multiple regression analysis to analyze the impact of U.S. rate regulation on individual insurer loss ratios for four lines of insurance in 1977 for the top- 15 insurers by premium volume in each line in 32 states. The use of individual insurer data provides a convenient method for testing a richer set of hypotheses than in previous work using aggregate data. Specifically, the model employed considers the impact of insurer investment income,

* Insurance Department - Wharton School, University of Pennsylvania.

${ }^{1}$ Miller [1981] and D'Arcy [1982] also analyzed data for homeowners coverage. O'Connor and Carlson [1979] compared mean loss ratios in prior approval and competitive states for a number of commercial lines.

${ }^{2}$ The results of Harrington [1985] suggest that the impact of rate regulation may differ across consumers in a given state, with residual market rates being affected to a greater extent than voluntary market rates. Also see Grabowski, Viscusi, and Evans [1985]. 
organizational form, and scale of operations on loss ratios. The inclusion of these variables may reduce the possibility of omitted variable bias in estimating the impact of rate regulation. Moreover, the influence of these variables on loss ratios is of interest in its own right. The study also departs from previous work in that regression models are estimated for four lines of business: private passenger auto, commercial auto, homeowners, and general liability.

Section 2 describes the model of individual insurer loss ratios. The data and estimation method are discussed in Section 3. Empirical results are presented in Section 4. Conclusions and suggestions for further study are offered in Section 5.

\section{Model specification}

A number of cost-related factors can be expected to influence loss ratios in the absence of regulation. Given these factors, the results of previous work, and data availability, the model employed posits that distribution method, ownership form, investment yield, scale of operations, market concentration, and type of rating law may affect by-line and by-state loss ratios for individual firms. The loss ratio used is defined as (IL + LAE)/(EP - D) where, for a given firm, line, and state, IL denotes incurred losses on direct business, LAE equals estimated loss adjustment expenses, EP equals direct earned premiums, and D denotes dividends to policyholders. ${ }^{3}$

A principal advantage of loss ratio comparisons for measuring the impact of rate regulation is that the inverse of the loss ratio may be viewed as the average price per dollar of benefits. The inclusion of LAE may produce a more appropriate measure of price than if only IL were to be included. For example, a better measure of benefits than incurred losses for thirdparty coverage might be the sum of claim payments and settlement expenses, since many or all of these expenses would be incurred by insureds to defend claims in the absence of coverage. ${ }^{4}$ While the data used for this study did not permit separate analysis of first-party and third-party coverage for auto and homeowners insurance, the inverse of the ratio of loss and loss adjustment expenses to earned premiums may be a better measure of price than the pure loss ratio for any line grouping that includes third-party coverage.

Evidence suggests that direct writers have lower operating expenses per dollar of losses or premiums than independent agency insurers (e.g., Joskow [1973] and Cummins and VanDerhei [1979]). ${ }^{5}$ The average share of the market written by direct writers also may differ between prior approval and competitive rating states for some lines. A dummy variable is

${ }^{3}$ LAE, which was calculated by the National Association of Insurance Commissioners (NAIC), equals IL times the ratio of the firms's nationwide net loss adjustment expenses to nationwide net incurred losses for the line. Hence, LAE reflects differences in loss adjustment expenses across firms, but not across states for a given firm.

${ }^{4}$ See Pauly, Kleindorfer, and Kunreuther [1986] for further discussion. A similar argument could be made for first-party coverage if the insured receives services that are classified as loss adjustment expenses.

${ }^{5}$ Whether customers of independent agency insurers receive valuable service for the higher prices has been disputed. See Joskow [1973], Cummins and VanDerhei [1979], and Pauly, Kleindorfer, and Kunreuther [1986]. 
included that equals one if the insurer is a direct writer and zero otherwise to control for the potential influence of distribution system on operating costs and thus loss ratios.

A dummy variable also is included that equals one for mutual insurers and zero for stock insurers. In a competitive market, loss ratios that do not reflect policyholder dividends would not be expected to differ for the two types of firms. Since mutual firm policyholders bear the risk of losses to policyholders' surplus, rather than shareholders, compensation of mutual owners for risk bearing in the form of policyholder dividends, lower premiums, or both could tend to produce higher dividend-adjusted loss ratios for mutual firms than for stocks. However, to the extent that compensation for risk bearing is small relative to total earnings or that most earnings are retained by both types of firms to provide security for policyholders, any long-run difference in loss ratios would be expected to be negligible. Moreover, the possibility of less effective control of management by policyholders than by shareholders, along with expense preference by managers (e.g., Williamson [1963]), conceivably could eliminate any such difference.

Short-run differences in loss ratios for stocks and mutuals could arise if mutuals adjust dividends in response to deviations of actual losses from the level expected when rates were set. Loss ratios for mutuals might be expected to exceed those for stocks in years in which losses are lower than expected and vice versa for years in which losses are higher than expected. Since the year analysed in this study may have been one in which losses were lower than expected (see below), a positive coefficient estimate for the mutual dummy would be consistent with this hypothesis.

Differences in the claims payout pattern across states or across consumers for a given line might cause loss ratios to differ across states, firms, or both. For example, differences in the legal environment could cause settlement policies to differ across states, and differences in claims settlement strategy. Some studies of insurance pricing have suggested using the ratio of liabilities generated by a line to premiums earned by the line as a proxy for the average amount of time that a dollar of premiums is invested prior to being paid out in benefits (e.g., Fairley [1979]). Data needed to derive such a measure are not readily available for individual firms for a given line, let alone on a by-state basis. Instead, this study employs NAIC data giving the ratio of an insurer's nationwide by-line allocation of investment income (including interest, dividends, rents, and realized capital gains or losses) to nationwide net written premiums for the line. ${ }^{6}$

The firm's national direct premiums written for the line is included to examine the influence of the overall scale of a firm's operations on its loss ratio. Evidence concerning returns to scale in the U.S. property-liability insurance industry generally suggests either constant or moderately inscreasing returns to scale (e.g., Joskow [1973] and Cummins and VanDerhei [1979]). Some evidence suggests increasing returns throughout the range of output, raising the question of why concentration is not higher in this market. One possibility is that imperfect

${ }^{6}$ The NAIC recommends that this ratio be used in allocating investment income to states (see NAIC [1974]). It varies across companies but not across states for a given company. A disadvantage of this measure is that it will reflect intercompany differences in portfolio yields as well as differences in funds generation by line. The work of Fairley [1979] and others suggests that differences in investment yields across firms will not influence competitive prices. 
information allows smaller and less efficient firms to survive; another is that, due to data limitations, the methodologies in these studies have not adequately controlled for non-scale factors that may influence costs. ${ }^{7}$

Increasing returns to scale for a line in the presence of imperfect information would be expected to produce a positive relationship between loss ratios and firm size if at least part of the cost savings for large firms was passed on to consumers. An insignificant relationship between size and loss ratios could indicate constant returns to scale. It also could be consistent with increasing returns to scale with all cost savings accruing to insurers. It seems unlikely, however, that imperfections in this market would be severe enough to prevent any relationship between prices and costs in the presence of increasing returns to scale. ${ }^{8}$

Concentration is relatively low for nost U.S. property-liability lines, and effective cartel pricing via rating bureaus is unlikely (see Danzon [1983] and Harrington [1984]). The results of studies that have included concentration ratios in models of statewide loss ratios (Ippolito [1979], U.S. General Accounting Office [1979], and D'Arcy [1982]) generally suggest that concentration does not significantly influence loss ratios. To provide further evidence in this regard, the statewide 4-firm concentration ratio for premiums written in a given line is included to allow for the possibility that increases in concentration at the state level could facilitate either active or tacit collusion among insurers and thus decrease loss ratios. ${ }^{9}$

Type of rate regulation was incorporated by classifying states with prior approval laws, modified prior approval laws, and file-and-use laws requiring prior approval for rate deviations by bureau members and subscribers as prior approval states. ${ }^{10} \mathrm{States}$ with file-and-use laws with bureau rates advisory only (hereafter file-and-use), use-and-file laws, and no-file laws were classified as competitive rating states. Two competitive rating dummy variables were included. The first equals one for states with a file-and-use law; zero otherwise. The second equals one for states with a use-and-file or no-file law; zero otherwise. The coefficient estimates for these variables will be estimates of the mean difference in loss ratios between

${ }^{7}$ Accounting data do not permit exclusion of expenditures on product and distribution network development that should be treated as current costs for purposes of assessing returns to scale. If small firms have higher levels of such expenditures than large firms, abias toward finding increasing returns to scale will result. Moreover, large firms may insure larger accounts than small firms, and expenses per account may decrese with account size. Lack of information on the number of accounts and the attendant omission of any variable to control for this influence again would lead to a bias toward finding increasing returns to scale.

${ }^{8}$ Given the data sources used, programming and other costs were significantly reduced by using combined national premiums for private passenger and commercial auto insurance in both the private passenger auto and commercial auto insurance equations. This procedure may be advantageous if there are common costs for private passenger and commercial business, but it also suggests caution in interpreting the results for the size variable for these lines. It also might have been preferable to use a measure of expected total claims rather than premiums (see Doherty [1981]). Measurement of expected total claims is problematic, however, and it is doubtful that the use of premiums would substantively influence the findings given the large range of firm sizes in the study. In any event, the results concerning the impact of rate regulation were not sensitive to the inclusion of the size variable.

${ }^{9}$ This procedure assumes that the effect of concentration on loss ratios, if any, will be similar for the top- 15 firms in the state. As a rough test of this assumtion, an interaction variable for 4-firm concentration and a dummy variable for the four largest firms in each state was included in the equations for the auto lines. The estimated coefficient for the interaction variable was not significant for either line.

${ }^{10}$ See Hanson, Dineen, and Johnson [1974] for details concerning each type of rating law. As is discussed later, states with state-made rates or mandatory bureau rates were not included in the sample. 
the states with these types of laws and the prior approval states after controlling for the influence of the remaining explanatory variables. The use of separate dummies permits the estimates to differ for the two competitive rating categories. There is no strong reason to expect any difference, but use-and-file and no-file laws allow insurers to change rates immediately, whereas file-and-use laws require a short waiting period, during which time regulators may examine and conceivably object to the rates filed.

Three hypotheses concerning the impact of rate regulation have been discussed in previous work: the excessive rate hypothesis, the regulatory lag hypotheses, and the consumer pressure hypothesis. The hypothesis that rate regulation produces excessive rates predicts that the estimates for the rating law dummies will be positive, i.e., loss ratios should be higher and average rates lower in competitive rating states. As usually formulated, the regulatory lag hypothesis suggests that loss ratios will be higher in competitive states than in prior approval states in years with favorable loss experience and vice versa for years with unfavorable experience. Loss ratios for 1977 are analyzed, the year with the lowest industry-wide loss ratio during 1973-85. The regulatory lag hypothesis would seem to suggest that loss ratios would be higher in competitive states in $1977 . .^{11}$ If consumer pressure influenced regulators to hold down rates in prior approval states, the estimates for the rating law dummies should be negative.

Previous work suggests that no-fault laws have had a positive impact on auto insurance loss ratios (see Witt and Urrutia [1983a] and Harrington [1984a, 1986]). The positive impact may reflect both the possible influence of no-fault laws on expected loss ratios and unanticipated growth in losses in no-fault states. In this study, the private passenger and commercial auto equations were estimated with and without two no-fault dummies. The first variable equals one for no-fault states with a monetary threshold less than or equal to $\$ 750$; zero otherwise. The second variable equals one for no-fault states with a monetary threshold greater than $\$ 750$ or a verbal threshold; zero otherwise. ${ }^{12}$

Following most previous studies, no attempt was made to control for differences in average pure premiums across states. The results of Harrington [1986] suggest that this omission is unlikely substantively to influence the findings. Since the individual firm loss ratios for auto insurance reflect combined experience for liability and physical damage coverages, it may have been desirable to include variables to reflect interstate and intercompany differences in the mix of liability and physical damage experience. While cost considerations precluded this approach, the authors know of no reason to expect that this omisssion would be likely to bias estimates for the rating law variables. Moreover, the investment yield variable should provide some control for intercompany differences in this regard, since its magnitude will be strongly influenced by the relative amount of liability and physical damage business written by a firm.

\footnotetext{
${ }^{11}$ Studies by Miller [1981] and others that have argued that regulatory lag will accentuate any underwriting cycle also would predict higher loss ratios in competitive rating states in 1977, since this year probably would be construed as a peak year in the underwriting profit cycle. The results of Harrington [1984a] using aggregate statewide data contradict both versions of the regulatory lag hypothesis, since they suggest significantly higher loss ratios in prior approval states throughout the 1976-81 period.

${ }^{12}$ States with "add-on" laws were not included in either category. (See Witt and Urrutia [1983a].) No attempt was made to control for the heterogeneity of no-fault laws with regard to differences in application between private passenger and commercial vehicles.
} 
Finally, the study also focuses on estimating the mean impact of rate regulation on loss ratios, rather than attempting to model possible interstate differences in the impact of a given type of law. ${ }^{13}$

\section{Data and estimation}

Loss ratios in 1977 for four lines in 32 states were analyzed for the top-15 insurers in terms of by-line and by-state premium volume. The 16 states that had had competitive rating laws in effect for at least two years for most lines as of 1977 were included. Sixteen prior approval states were then selected using a strategy designed both to favor selection of the largest states in terms of population and to achieve a reasonable geographical spread. States with statemade rates or mandatory bureau rates for any of the four lines were excluded to improve the homogeneity of the prior approval group. ${ }^{14}$

The data source for calculating the loss ratio, investment yield, and 4-firm concentration ratio was the 1977 NAIC Profitability and Market Share Data tape. The 1977 NAIC PropertyLiability Early Warning Data tape was used to obtain the national direct written premiums for each line for each firm. Information on ownership type was obtained from Best's Reports-Property and Casualty Edition. Best's also was used to classify firms as independent agency or direct writers if this information was not known to the authors or available in previous studies (e.g., Cummins and CVanDerhei [1979]). Details on no-fault laws were obtained from the American Insurance Association (1978).

Preliminary estimates were obtained using ordinary least squares (OLS). The adjusted multiple correlation coefficients for each line were less than.15. This is not surprising in view of the substantial variability in loss ratios using state data for individual firms. As expected

\footnotetext{
${ }^{13}$ Harrington [1986] used a random coefficient procedure to estimate the impact of regulation on the statewide loss ratio in each prior approval state. While the findings suggested significant cross-state variation, the estimated mean effect of regulation using this procedure was similar to that obtained under the assumption that the impact of regulation was constant in prior approval states. Pauly, Kleindorfer, and Kunreuther [1986] included variables both to reflect differences in the abilits of consumers across states to obtain and process information and to control for possible interstate differences in underwriting costs and in consumer demand for quality. Their results do not provide a compelling reason for including such variables.

${ }^{14}$ The competitive rating states were California, Colorado, Connectivut, Florida, Georgia, Idaho, Illinois, Minnesota, Missouri, Montana, Nevada, New York (for homeowners and general Liability), Oregon, Utah, Virginia, and Wisconson. The prior approval states were Albama, Arizona, Arkansas, Delaware, Indiana, Iowa, Kansas, Kentucky, Michigan, New Hampshire, New Jersey, New York (for both auto lines), North Dakota, Ohio, Pennsylvania, South Carolina, and Washington. The classification was based on NAIC tables giving the type of law in each state as of September, 1973, and December, 1978. (The 1973 table is reproduced in Hanson, Dineen, and Johnson [1974].)

Effective dates for changes in rating laws that occurred during the 1973-78 period were verified by examining the state codes. Connecticut was treated as having a file-and-use law for all four lines, although it was listes as having prior approval regulation for no-fault auto coverages. After the empirical work was completed, it was discovered that the NAiC lists had incorrectly classified Ohio as having a fileand-use law with deviations by bureau members and subsribers subject to prior approval, as opposed to a file-and-use law without prior approval for such deviations, for both auto lines and general liability insurance. Any misclassification would be expected to bias the results towards the null nypothesis of no impact of regulation, in contrast to the findings of this study.
} 
given the law of large numbers, plots of the loss ratios and OLS residuals against statewide written premiums for the firms suggested substantial size-related heteroscedasticity. The results reported in the paper were obtained using weighted least squares (WLS) with the square root of a firm's statewide written premiums as the weight for each firm. ${ }^{15}$

\section{Results}

Sample means and standard deviations of the firms' by-state loss ratios for each line are shown in Table 1 for the overall sample and according to type of regulation and distribution system. The means are greater for the prior approval states for each line except general liability. The means are greater for the direct writers than for the independent agency insurers, as would be expected if direct writers have lower operating expenses. The large differences in the

Table 1: Summary statistics for by-state, by-line, by-company loss ratios in 1977.

\begin{tabular}{|c|c|c|c|c|c|c|}
\hline \multirow[b]{2}{*}{ Line } & \multirow[b]{2}{*}{ Statistic } & \multirow[b]{2}{*}{$\begin{array}{c}\text { All } \\
\text { Observations }\end{array}$} & \multicolumn{2}{|c|}{ Rating Law } & \multicolumn{2}{|c|}{ Distribution System } \\
\hline & & & $\begin{array}{c}\text { Prior } \\
\text { Approval }\end{array}$ & $\begin{array}{c}\text { Competitive } \\
\text { Rating }\end{array}$ & $\begin{array}{c}\text { Independent } \\
\text { Agency }\end{array}$ & $\begin{array}{c}\text { Direct } \\
\text { Writers }\end{array}$ \\
\hline Private & Mean & .724 & .753 & .691 & .699 & .757 \\
\hline Passenger & $\hat{\sigma}$ & .118 & .123 & .104 & .120 & .107 \\
\hline Auto & $\mathrm{n}$ & 470 & 250 & 220 & 265 & 205 \\
\hline \multirow{3}{*}{$\begin{array}{l}\text { Commercial } \\
\text { Auto }\end{array}$} & Mean & .642 & .658 & .622 & .618 & .733 \\
\hline & $\hat{\sigma}$ & .230 & .213 & .249 & .216 & .261 \\
\hline & $\mathrm{n}$ & 467 & 251 & 216 & 370 & 97 \\
\hline \multirow[t]{3}{*}{ Homeowners } & Mean & .611 & .647 & .574 & .605 & .627 \\
\hline & $\hat{\sigma}$ & .175 & .196 & .144 & .181 & .161 \\
\hline & $\mathrm{n}$ & 474 & 238 & 236 & 340 & 134 \\
\hline General & Mean & .521 & .509 & .532 & .486 & .776 \\
\hline \multirow{2}{*}{ Liability } & $\hat{\sigma}$ & .545 & .494 & .592 & .499 & .768 \\
\hline & $\mathrm{n}$ & 475 & 237 & 238 & 418 & 57 \\
\hline
\end{tabular}

Note: Mean denotes sample mean, ô denotes sample standard deviation, and n denotes number of observations. The prior approval category includes states with laws classified as prior approval, modified prior approval, and file-and-use with deviations by bureau mambers and subscribers subject to prior approval. The competitive rating category includes states with laws classified as file-and-use, use-andfile, and no-file. The number of observations for each line does not equal 470 (32 states times 15 companies) due to the exclusion of companies with missing data.

\footnotetext{
${ }^{15}$ The estimation procedure was not modified to allow for either fixed or random effects for states or firms. Given that some of the variables do not vary across states for a given firm and others do not vary across firms for a given state, the technique of least squares with firm and state dummies could not be used. It was also decided that allowing for random state effects within an error components framework for unbalanced data would not be worth the extra computational effort with these data. If the disturbances are not independent due to such effects, the estimation procedure used will produce unbiased coefficient estimates provided that the effects are not correlated with the explanatory variables. However, the possibility of bias in the estimated standard errors suggests caution in interpreting the findings.
} 
means between the groups of insurers for the commercial lines, especially for general liability, probably are at least partially attributable to adverse loss experience for some of the direct writers. The substantially larger standard deviations for general liability than for the remaining lines may reflect the greater heterogeneity among insured exposures and inherent riskiness of this line.

\subsection{Private passenger auto}

Equation (1).The results of estimating the loss ratio model for each line are shown in Table 2. The estimated coefficients for the competitive rating law dummies are both negative and highly significant for private passenger auto insurance in equation (1), which does not

Table 2: WLS regression results for by-line, by-state, by-company loss ratios in 1977

\begin{tabular}{|c|c|c|c|c|c|c|}
\hline \multirow{2}{*}{$\begin{array}{l}\text { Independent } \\
\text { Variable }\end{array}$} & \multicolumn{2}{|c|}{ Private Passenger Auto } & \multicolumn{2}{|c|}{ Commercial Auto } & \multirow{2}{*}{ Homeowners } & \multirow{2}{*}{$\begin{array}{l}\text { General } \\
\text { Liability }\end{array}$} \\
\hline & (1) & (2) & (1) & (2) & & \\
\hline Constant & $\begin{array}{r}.6337 \\
(20.09)\end{array}$ & $\begin{array}{r}.5701 \\
(18.62)\end{array}$ & $\begin{array}{l}.5227 \\
(9.66)\end{array}$ & $\begin{array}{l}.5090 \\
(9.53)\end{array}$ & $\begin{array}{r}.8317 \\
(15.94)\end{array}$ & $\begin{array}{r}-1.1712 \\
(0.96)\end{array}$ \\
\hline File-and-Use & $\begin{array}{r}-.0613 \\
(4.40)\end{array}$ & $\begin{array}{r}-.0604 \\
(4.68)\end{array}$ & $\begin{array}{r}-.0628 \\
(2.44)\end{array}$ & $\begin{array}{r}-.0567 \\
(2.25)\end{array}$ & $\begin{array}{r}-.0630 \\
(3.95)\end{array}$ & $\begin{array}{r}-.0286 \\
(0.44)\end{array}$ \\
\hline $\begin{array}{l}\text { Use-and-File } \\
\text { and No-File }\end{array}$ & $\begin{array}{r}-.0875 \\
(9.93)\end{array}$ & $\begin{array}{r}-.0704 \\
(8.74)\end{array}$ & $\begin{array}{r}-.0835 \\
(4.37)\end{array}$ & $\begin{array}{r}-.0622 \\
(3.33)\end{array}$ & $\begin{array}{r}-.0509 \\
(3.85)\end{array}$ & $\begin{array}{r}.0196 \\
(0.35)\end{array}$ \\
\hline Direct Writer & $\begin{array}{r}.0379 \\
(3.55)\end{array}$ & $\begin{array}{r}.0378 \\
(3.81)\end{array}$ & $\begin{array}{r}.1335 \\
(5.31)\end{array}$ & $\begin{array}{l}.1484 \\
(5.93)\end{array}$ & $\begin{array}{r}.0785 \\
(3.94)\end{array}$ & $\begin{array}{r}.2791 \\
(1.18)\end{array}$ \\
\hline Mutual & $\begin{array}{l}.0225 \\
(2.55)\end{array}$ & $\begin{array}{l}.0270 \\
(3.30)\end{array}$ & $\begin{array}{r}.0262 \\
(1.10)\end{array}$ & $\begin{array}{l}.0160 \\
(0.68)\end{array}$ & $\begin{array}{r}-.0002 \\
(0.01)\end{array}$ & $\begin{array}{r}.0511 \\
(0.21)\end{array}$ \\
\hline Investment Yield & $\begin{array}{r}2.0095 \\
(6.53)\end{array}$ & $\begin{array}{c}1.9388 \\
(6.66)\end{array}$ & $\begin{array}{l}.5083 \\
(1.07)\end{array}$ & $\begin{array}{l}.0667 \\
(0.14)\end{array}$ & $\begin{array}{l}.6808 \\
(0.43)\end{array}$ & $\begin{array}{r}3.0270 \\
(6.19)\end{array}$ \\
\hline National Premiums & $\begin{array}{r}-.0001 \\
(4.18)\end{array}$ & $\begin{array}{r}-.0001 \\
(4.90)\end{array}$ & $\begin{array}{r}-.0003 \\
(2.05)\end{array}$ & $\begin{array}{r}-.0004 \\
(2.44)\end{array}$ & $\begin{array}{r}-.0001 \\
(2.80)\end{array}$ & $\begin{array}{r}-.0006 \\
(2.59)\end{array}$ \\
\hline 4-Firm Concentration & $\begin{array}{l}.0007 \\
(1.13)\end{array}$ & $\begin{array}{l}.0015 \\
(2.55)\end{array}$ & $\begin{array}{l}.0050 \\
(2.30)\end{array}$ & $\begin{array}{r}.0042 \\
(2.20)\end{array}$ & $\begin{array}{r}-.0054 \\
(7.40)\end{array}$ & $\begin{array}{l}-0039 \\
(1.00)\end{array}$ \\
\hline $\begin{array}{l}\text { No-Fault: Low } \\
\text { Threshold }\end{array}$ & & $\begin{array}{l}-0876 \\
(8.80)\end{array}$ & & $\begin{array}{r}.0733 \\
(3.81)\end{array}$ & & \\
\hline $\begin{array}{l}\text { No-Fault High } \\
\text { Threshold }\end{array}$ & & $\begin{array}{l}.0225 \\
(2.41)\end{array}$ & & $\begin{array}{l}.0750 \\
(3.94)\end{array}$ & & \\
\hline
\end{tabular}

Note: Absolute values of $t$-values are in parentheses below the coefficient estimates. 
include the no-fault dummies. The estimated difference in loss ratios between prior approval states and file-and-use states is six percent. The estimated difference between prior approval states and states with use-and file or no-file laws is nine percent. These results, which are consistent with the mean differences shown in Table 1, indicate considerably lower average prices for prior approval states.

The estimated coefficient for the direct writer dummy is positive and significant as expected. The estimate for the mutual dummy variable also is positive and significant, indicating that mutual insurers had loss ratios about two percentage points higher than stock insurers, other things equal. ${ }^{16}$ The investment yield variable is positively and significantly related to the loss ratio. The magnitude of the estimate implies a two percentage point change in the loss ratio for a one percentage point change in investment gain relative to earned premiums. This seemingly large estimated response could reflect data problems such as differences in investment income allocation procedures or investment policies across firms.

Firm size is negatively and significantly related to the loss ratio. This result is surprising because it implies that large firms have higher average prices than small firms, other things equal. Since the national premiums variable was expressed in $\$ 10,000,000$ s, the estimate implies a one percentage point decrease in the loss ratio for each billion dollar increase in premiums ${ }^{17}$ The possibility exists that large firms culd provide more services with higher costs than small firms. Alternatively, if the smaller firms in the sample tended to insure higher risk drivers than large firms. they could have lower expense ratios if underwriting expenses per insured exposure increase less than proportionately with expected losses. ${ }^{18}$

Alternatively, the result for the size variable could reflect a positive relationship between firm size and underwriting profit margins. If so, the implications would not be clear in the absence of information concerning the fair level of profit margins. One possibility would be that large firms achieved fair returns, while small firms experienced economic losses, perhaps in an attempt to increase market share through price reductions or relaxation of underwriting standards. Small firms also are more likely to use bureau rates (Danzon [1983]). Bureau rates possibly may not have caught up with rapid increases in loss costs during the mid-1970s. Large firms, which generally price independently, may have used more accurate forecasts of expected claims. A final possibility is that large firms earned economic profits. ${ }^{19}$

16 This result could indicate increased dividends by mutals in a profitable year. It also may be affected by the fast that most of the direct writers in the sample for this line were mutuals, whereas most of the stock insurers used independent agents. The positive correlation between the direct writer and mutual dummies may make it difficult to sort out the influence of the variables.

${ }^{17}$ The largest two auto insurers in the sample were State Farm and Allstate with $\$ 4.0$ and $\$ 2.8$ billion in premiums, respectively.

${ }^{18}$ While the returns to scale literature is inconsistent with both of these explanations, they cannot be ruled out given the possible limitations of these studies described in footnote 7.

${ }^{19}$ Of course, the negative relationship between firm size and loss ratios could reflect specification error or multicollinearity. With regard to the latter possibility, the three largest auto insurers in the sample were direct writers. Positive correlation between the direct writer dummy and the size variable and the attendant negative correlation in the sampling errors for their estimated coefficients conceivably could have produced the negative coefficient for the size variable. 
The results for the concentration variable for equation (1) for private passenger auto provide no evidence that higher levels of concentration are associated with lower loss ratios and thus higher average prices. In fact, the estimated coefficient is positive, although insignificant in equation (1). A positive relationship could reflect the high correlation between 4-firm concentration and direct writer market share. An alternative conjecture is that direct writers expand in a market by accepting progressively higher risk drivers and that underwriting costs for both independent agency insurers and direct writers increase at a less than proportionate rate with expected losses. If so, an increase in direct writer share would be associated with increases in the average pure premiums and hence loss ratios for insurers in both groups. ${ }^{20}$

Equation (2). The results for the regulatory variables, the direct writer and mutual dummies, investment yield, and national premiums in equation (2) for private passenger auto are similar to those for equation (1). The estimated coefficients for the regulatory variables decline somewhat when the no-fault dummies are included, but they still are negative and significant, indicating lower loss ratios in competitive rating states. The estimated coefficient for 4-firm concentration increases in magnitude and is significant in equation (2). ${ }^{21}$ The estimated coefficients for the no-fault variables are both positive and significant, which is consistent with earlier work. ${ }^{22}$

\subsection{Commercial auto}

The results for the commercial auto equations generally are similar to those for private passenger auto. While slightly smaller in magnitude, the estimated coefficients for the rating law variables are again negative and significant. The estimated coefficients for the direct writer dummy variable are positive and significant. The magnitude of these coefficients is consistent with the difference in means shown in Table 1 . The estimates for the mutual dummy are positive but not significant, perhaps because much of the commercial auto business that is written by stock companies is experience rated and thus similar to participating business written by mutuals. The estimates for the investment yield variable are positive for both equations, but they are not significant and are much lower than for the private passenger auto equations. The estimate for this variable also declines when the no-fault dummies are included.

The results for the firm size variable again indicate a statistically significant and negative relationship between scale of operations and loss ratios. The absolute magnitude of the coefficient estimates is much larger than for the private passenger auto equations, implying a 3-4 percentage point decrease in the loss ratio for each billion dollar increase in national premiums. As was the case for equation (2) for private passenger auto, the estimates for the

${ }^{20}$ In general, the high correlation between direct writer share and concentration, coupled with the possibility that direct writers are more efficient, may negate the implication that higher concentration is likely to be destrimental to comsumers.

${ }^{21}$ The concentration variable is in percent. The estimate for equation (2) implies an increase in the loss ratio of 1.5 percentage points for each 10 percentage point increase in 4-firm concentration.

22 The greater magnitude of the estimate for the low-threshold dummy that for the high-threshold dummy may reflect adverse loss experience in states with low thresholds during this year. Three of the states in the low-threshold category subsequently modified or repealed their no-fault laws, partially in response to rapid increases in auto insurance costs under the original laws. 
4-firm concentration variable are positive and significant. The magnitude of the estimates is considerably larger, implying a 4-5 percentage point increase in the loss ratio for a 10 percentage point increase in 4-firm concentration. Again, this result is difficult to interpret and probably indicates that concentration is picking up the influence of omitted variables. The results for the no-fault variables also indicate significantly higher loss ratios in no-fault states for commercial auto insurance, but the magnitude of the estimate is similar for both threshold categories.

\subsection{Homeowners}

The findings for the rating law variables for homeowners are similar to those for auto insurance. The estimate for the direct writer variable again is positive and significant. The estimate for the mutual dummy is negative, in contrast to the auto results, but not significant. The results for the size variable indicate a significantly negative relationship between loss ratios and scale of operations. The magnitude of the estimate is similar to that for private passenger auto insurance. In contrast to the auto results, the concentration variable is negatively and significantly related to the loss ratio, implying a 5 percentage point reduction in the loss ratio for a 10 percentage point increase in 4 -firm concentration. This result should be interpreted cautiously in view of the possibility that 4-firm concentration could be correlated with omitted factors that may affect homeowners underwriting expenses and thus loss ratios. However, the negative estimate could be consistent with noncompetitive behavior in this line.

\subsection{General liability}

The results for general liability differ substantially from those for the other lines. This may be due to greater variability in losses and greater heterogeneity among insured exposures for this line. The estimated coefficients for the rating law variables are not significant. This finding may reflect the pricing flexibility that exists under experience-rating procedures in regulated states. It also might indicate pro forma approval of rate filings. The only significant variables are investment yield and national premiums. The estimate for investment yield is positive as expected, although its magnitude would appear to be unreasonably large. The estimate for the firm size variable is positive. While this result might indicate increasing returns to scale, a more plausible explanation is that larger firms insure a proportionately greater number of large commercial risks that may entail lower underwriting costs per dollar of expected losses than small commercial risks.

\section{Conclusions}

The results suggest that loss ratios were significantly lower and thus average prices significantly higher in competitive rating states than in prior approval states for private passenger auto, commercial auto, and homeowners insurance during 1977. These findings, which are consistent with those of recent work using aggregate data for private passenger auto insurance, may indicate that regulators responded to consumer pressure by holding rates below levels that would have occured under pricing freedom. 
Firm size, as measured by nationwide premiums in a line, was found to be negatively and significantly related to loss ratios in each line except general liability. Further research should investigate whether this relationship persists in other years, and, if so, whether the result indicates higher profits for large firms. The findings concerning market concentration provide no evidence of harmful effects for the auto lines or for general liability insurance. The significantly negative relationship between 4-firm concentration and loss ratios for homeowners indicates the need for additional work to determine whether noncompetitive behavior exists in this line.

\section{REFERENCES}

AMERICAN INSURANCE ASSOCIATION [1978]: Summary of Selected State Laws and Regulations Relating to Automobile Insurance, American Insurance Association, New York, N.Y.

BEST'S INSURANCE REPORTS, PROPERTY \& CASUALTY EDITION, A.M. Best Co., Oldwick, N.J.

CUMMINS, J.D., and VANDERHEI, J. [1979]: "A note on the relative efficiency of property-liability insurance distribution systems", Bell Journal of Economics, 10 (Autumn 1979), 709-719.

DANZON, P. [1983]: "Rating bureaus in U.S. property-liability insurance markets: Anti or pro-competitive?", Geneva Papers on Risk and Insurance, 8 (October 1983), 371-402.

D'ARCY, S. [1982]: “An economic theory of insurance regulation”, Ph.D. dissertation, University of Illinois.

DOHERTY, N. [1981] : "The measurement of output and economies of scale in property-liability insurance", Journal of Risk and Insurance, 48 (September 1981), 390-402.

FAIRLEY, W. [1979]: "Investment income and profit margins in property-liability insurance: Theory and empirical results", Bell Journal of Economics, 10 (Spring 1979), 192-210.

GRABOWSKI, H., VISCUSI, K., and EVANS, W. [1985]: "The effects of regulation on the price and availability of automobile insurance", paper presented at Nineteenth International Atlantic Economic Conference, Rome.

HANSON, J., DINEEN, R., and JOHNSON, M. [1974]: "Monitoring competition: A means of regulating the property and liability insurance business", Supplement to the 1974 NAIC Proceedings.

HARRINGTON, S. [1984a]: "The impact of rate regulation on automobile insurance loss ratios: Some new empirical evidence", Journal of Insurance Regulation, 3 (December 1984), 182-202.

HARRINGTON, S. [1984b] : "The impact of rate regulation on prices and underwriting results in the property-liability insurance industry: A survey", Journal of Risk and Insurance, 51 (December 1984), $577-623$.

HARRINGTON, S. [1985]: "Cross-subsidization in auto insurance: The relationship between voluntary and residual market rates and rate regulation”, paper presrented at 1985 Meeting of the American Risk and Insurance Association, Vancouver, B.C.

HARRINGTON, S. [1986] : "A note on the impact of auto insurance rate regulation", forthcoming, Review of Economics and Statistics.

IPPOLITO, R. [1979]: "The effects of price regulation in the automobile insurance industry", Journal of Law and Economics, 22 (April 1979), 55-89.

JOSKOW, P. [1973]: "Cartels, competition and regulation in the property-liability insurance industry", Bell Journal of Economics and Management Science, 4 (Autumn 1973), 375-427. 
MILLER, E. [1981]: "Rate regulation and profitability in automobile and homeowners insurance", paper presented at the 1981 Meeting of the American Risk and Insurance Association, Kansas City, Mo.

NATIONAL ASSOCIATION OF INSURANCE COMMISSIONERS, [1974]: "Statement on profitability in property and liability insurance by state and by line", NAIC Proceedings, (1974, vol. I), 196-197.

O'CONNOR, P., and CARLSON, K.: "Open competitive vs. prior approval: Property and liability loss ratios, concentration ratios and operating profits", paper presented at 1979 Annual Conference of the Society of Insurance Research, reprinted in The National Underwriter-Property and Casualty Edition, (December 7, 1979), 22.

PAULY, M., KLEINDORFER, P., and KUNREUTHER, H. [1961]: "Regulation and quality competition in the U.S. insurance industry", in A Cross-National Study of Insurance Regulation, J. Finsinger and M. Pauly (eds.), St. Martins Press, London.

U.S. GENERAL ACCOUNTING OFFICE [1979]: Issues and Needed Improvements in State Regulation of the Insurance Business, U.S. General Accounting Office, Washington, D.C.

WILLIAMSON, O. [1963]: "Managerial discretion and business behavior", American Economic Review, 53 (December 1963), 1032-1057.

WITT, R., and URRUTIA, J. [1983a]: "A comparative economic analysis of tort liability and no-fault compensation systems in automobile insurance", Journal of Risk and Insurance, 50 (December 1983), 631-667.

WITT, R., and URRUTIA, J. [1983b]: "Price competition, regulation, and systematic underwriting risk in automobile insurance”, Geneva Papers on Risk and Insurance, 8 (October 1983), 403-429. 